\title{
EJECUCIÓN ESPECIAL DE SENTENCIA APELADA Y LA SANCIÓN OPORTUNA DE INFRACCIONES ADMINISTRATIVAS EN EL DISTRITO DE WÁNCHAQ
}

\section{Special execution of appealed judgment and the timely punishment of administrative offenses in the district of Wanchaq}

\author{
Marco Antonio Abarca Alfaro 1,a, \\ ${ }^{1}$ Universidad Andina del Cusco, Cusco, Perú. \\ ${ }^{a}$ Maestro en Derecho Civil y Derecho Procesal Civil \\ ”marcosayayin@hotmail.com
}

\begin{abstract}
Resumen
El articulo describe los resultados de la tesis «Ejecución especial de sentencia apelada y la sanción oportuna de las infracciones administrativas en el distrito de Wánchaq»; cuyo problema central es la impunidad de las sanciones administrativas a partir de la suspensión de estas, cuando son judicializadas. El principal objetivo es determinar si la implementación del nuevo instituto jurídico procesal —ejecución especial de la sentencia apelada-, contribuirá con la sanción oportuna de las infracciones administrativas en el distrito de Wánchaq. Respecto a la metodología empleada la investigación destaca por su enfoque socio-jurídico, para ello se han determinado las variables independiente y dependiente de la hipótesis, las cuales han sido identificadas a través de los indicadores correspondientes que, a su vez, han sido operacionalizados, valiéndonos para ello de las técnicas e instrumentos de recolección de datos, como son: consulta bibliográfica, entrevistas, reporte electrónico de expedientes judiciales, registro fílmico y fotográfico. La población de estudio está integrada por todos los procesos sobre 'nulidad de resolución administrativa' seguidos contra la Municipalidad Distrital de Wánchaq, que asciende a 53 expedientes judiciales. Concluyendo, la dotación de medios para la ejecución de las resoluciones administrativas de sanción a través de la incorporación del cumplimiento de la sentencia apelada, solucionará el problema, puesto que posibilitará que la municipalidad demandada, cuando obtenga sentencia que desestime la demanda de los infractores, podrá pedir la ejecución inmediata de la sentencia que, a su vez, deberá de disponer la ejecución de la sanción administrativa.

Palabras clave: Impunidad de las sanciones administrativas, trámite largo de los procesos judiciales en el contexto peruano, suspensión de sanciones administrativas, cuando están son judicializadas.
\end{abstract}

\begin{abstract}
The article describes the results of the thesis "Special execution of the appealed sentence and the timely sanction of administrative infractions in the district of Wánchaq"; whose central problem is the impunity of the administrative sanctions, from the suspension of these, when they are judicialized. The main objective is to determine if the implementation of the new legal institute-special execution of the sentence appealed-will contribute to the timely sanction of administrative infractions in the district of Wánchaq, regarding the methodology used, the research is notable for its socio-economic approach. For this purpose, we have determined the independent and dependent variables of the hypothesis, which have been identified through the corresponding indicators that, in turn, have been operationalized, using the data collection techniques and instruments to do so, such as: bibliographical consultation, interviews, electronic report of judicial files, film and photographic record. The study population is made up of all the proceedings on 'nullity of administrative resolution' against the District Municipality of Wánchaq, amounting to 53 court records. Concluding the endowment of means for the execution of the administrative resolutions of sanction through the incorporation of compliance with the sentence appealed, will solve the problem, since it will make it possible for the municipality sued, when it obtains a judgment that dismisses the claim of the offenders, request the immediate execution of the sentence that, in turn, must order the execution of the administrative sanction.
\end{abstract}

Keywords: Impunity of administrative sanctions, long processing of judicial processes in the Peruvian context, suspension of administrative sanctions, when they are prosecuted

Citar como: Abarca, M. (2018). Ejecución especial de sentencia apelada y la sanción oportuna de infracciones administrativas en el distrito de Wánchaq. Rev Yachay, 7(1) ,404-410.

Recibido: 2018-09-16; Aceptado

Rev. Yachay volumen (7) Número (1), enero-diciembre 2018 


\section{Introducción}

La impunidad de las infracciones municipales evidencia pues, la concurrencia de varios factores —entre ellos la falta de educación, pérdida del principio de autoridad, incapacidad de las autoridades-, sin embargo, en la presente investigación nos focalizamos en el factor normativo, ya que consideramos que una de las causas principales para la consolidación de la impunidad de infracciones administrativas radica en la permisividad del ordenamiento jurídico vigente.

La sanción contenida en la resolución administrativa será materia de impugnación administrativa y judicial, suspendiéndose de esta manera, todo intento de sanción, dilación que significa en la realidad peruana: tres años promedio para la ejecución de la sanción mientras se obtenga una decisión firme en el ámbito judicial; tiempo que contribuirá a que la población afectada por la infracción administrativa, considere no sentirse en un sistema democrático y de imperio de la ley sino, por el contrario, se adherirá a la creencia colectiva de que la justicia solo es para los ricos y poderosos, consolidándose la imagen de una sociedad indiferente.

La Ley Orgánica de Municipalidades n. 27972 , establece que es competencia de las municipalidades velar por el cumplimiento de las leyes, ordenanzas y demás normas jurídicas, en tal sentido, ostentan la capacidad sancionadora conforme al art. 46 de la citada ley, por el cual se faculta a las municipalidades iniciar el procedimiento administrativo sancionador, con el fin de castigar a los administrados infractores del distrito de Wánchaq (ámbito territorial de esta investigación) y donde está vigente la Ordenanza Municipal n. ${ }^{\circ} 101-2007$ $\mathrm{MDW} / \mathrm{C}$, sobre el 'Nuevo régimen de aplicación de sanciones', que fija el procedimiento sancionador, tipifica las conductas infractoras y las sanciones respectivas.

Ante una eventual infracción por parte de los administrados, la Municipalidad Distrital de Wánchaq, a través de su órgano de fiscalización, realiza la diligencia respectiva para constatar la infracción, iniciándose el procedimiento administrativo sancionador y emitiéndose la resolución de sanción y multa la misma que, en la mayoría de casos, es objeto de recursos impugnatorios administrativos (Perú, 2001, pág. Art. 207), con la finalidad de agotar la vía administrativa y cumplir el requisito de procedibilidad para la futura interposición de la demanda contencioso-administrativa sobre nulidad de resoluciones administrativas.

Interpuesta la demanda por el administrado (que ahora se convierte en demandante contra la municipalidad) para cuestionar la resolución administrativa con el objeto de que se declare nula judicialmente; sin embargo, en la mayoría de casos los procesos judiciales tramitados contra la Municipalidad Distrital de Wánchaq sobre nulidad de resolución administrativa, a través de la Procuraduría Pública (órgano de defensa), se obtiene sentencias que declaran infundadas o, en su caso improcedentes estas demandas, lo que confirma la validez y legalidad de las resoluciones administrativas de sanción.

Ahora bien, pese a que desde la interposición de la demanda hasta la emisión de la sentencia de primera instancia ha transcurrido en promedio un año, las resoluciones administrativas (municipales) de sanción siguen suspendidas en su ejecución, mientras se obtenga una sentencia consentida con calidad de cosa juzgada, lo cual no ocurre inmediatamente luego de haber obtenido la sentencia, ya que, esta es apelada por el demandante/administrado, elevándose el proceso a la segunda instancia. Hasta aquí han transcurrido, por lo menos, más de dos años sin que se puedan ejecutar las resoluciones administrativas de sanción y, con ello, buscar erradicar las conductas infractoras.

\section{Objetivos de la investigación}

\section{Objetivo general}

Determinar si la implementación de la ejecución especial de la sentencia apelada contribuirá con la sanción oportuna de las infracciones administrativas en el distrito de Wánchaq.

\section{Objetivos específicos}

- Describir el problema generado por la falta de sanción debido al inicio del proceso judicial de nulidad de resolución administrativa.

- Identificar los factores que imposibilitan la ejecución oportuna de la sanción administrativa.

\section{Hipótesis}

Dado que la ejecución especial de la sentencia apelada se implementará a través de una ley, esta contribuirá como mecanismo legal para que los jueces puedan disponer la ejecución oportuna de la sanción administrativa, a pesar de que la sentencia haya sido apelada. 


\section{Justificación}

Hasta aquí todo lo desarrollado describe cómo la impunidad de las infracciones cometidas por los administrados es avalada por el mismo sistema jurídico, lo que a criterio nuestro debe ser objeto de modificación en la legislación pertinente; en tal sentido, consideramos que esta investigación cumple suficientemente con los criterios de justificación, como por ejemplo:

- Conveniencia: La investigación servirá para poder identificar las causas de naturaleza jurídica que contribuyen a la dilación y la impunidad de las infracciones.

- Impacto social: La principal perjudicada con la falta de sanción oportuna a los administrados infractores es la sociedad wanchina, pues el continuo funcionamiento de locales sin licencia municipal como: bares y cantinas, la construcción ilegal de edificaciones; entre otros, originan delincuencia, drogadicción, impunidad, y consecuente masificación de infracciones en el distrito de Wánchaq.

- Análisis costo beneficio: La propuesta de ley al establecer la «ejecución especial de sentencia apelada», no irrogará gasto alguno al tesoro público, pues es un mecanismo de naturaleza procesal que se corresponde con el deber general de los órganos jurisdiccionales de administrar justicia y, por el contrario, los beneficios obtenidos a partir de la promulgación de este proyecto de ley serán notorios, ya que se contribuirá a la sanción oportuna de las infracciones administrativas.

- Implicancia práctica: Los resultados de la investigación y su eventual producto beneficiarán a la misma sociedad wanchina, porque se buscará solucionar el problema social ocasionado por la dilación innecesaria de las sanciones municipales; asimismo estamos seguros, que los resultados del presente trabajo podrán adaptarse a la realidad de otras municipalidades del país.

- Valor teórico normativo: Los resultados de la presente investigación contribuirán y servirán como base para la eventual creación de un nuevo instituto jurídico procesal, dentro de la legislación especial claro está, que permita la ejecución oportuna de las sanciones administrativas, a pesar de que estas hayan sido judicializadas, instituto que se inspira en la 'teoría de la medida cautelar por sentencia favorable' contenida en el artículo 615 del CPC.

- Aportaciones para la enseñanza: La investigación contribuirá a comprender las deficiencias y vacíos del sistema jurídico procesal peruano.

- Utilidad metodológica: El presente trabajo podrá servir como modelo para futuras investigaciones que pretendan proponer modificaciones en el ordenamiento jurídico, sobre la base de la investigación socio-jurídica.

\section{Antecedentes de la investigación}

Habiéndose realizado la búsqueda sobre la existencia de estudios que traten sobre el tema, a través de la investigación de tesis -en los distintos bancos electrónicos de las páginas web de las universidades del país-, se indica que: no se ha encontrado estudio alguno que sirva como antecedente directo de la presente investigación, por lo que, esta tiene el carácter de primigenia en su especie al abordar el problema de la impunidad de las infracciones administrativas a partir de su judicialización; sin embargo, citando a Alejandro Solís Espinoza, quien señala lo siguiente: «Si no existen trabajos relacionados a nuestro objeto de estudio, se debe indagar acerca de estudios afines o cercanos que nos pueden servir para el desarrollo de nuestro proyecto» (Solís Espinoza, 2008), en tal sentido, debe destacarse la presencia de sentencias jurisprudenciales que, de manera referencial, abordan el tema, como las contenidas en las resoluciones del Tribunal Constitucional en los expedientes: $n .^{\circ}$ 339-2002-AA-TC; $n .^{\circ}$ 3330-2004-AA-TC y el expediente $n .^{\circ}$ 2802-2005-AA-TC

\section{Contribución del autor:}

La elaboración de un proyecto de ley que busca solucionar el problema de la impunidad de sanciones administrativas como consecuencia de la suspensión de su ejecución, por la mera judicialización de las mismas. Para ello, este proyecto de ley busca insertar la prerrogativa de que el juez disponga inmediatamente la ejecución de la resolución administrativa de sanción en la sentencia desestimatoria; asimismo, este proyecto de ley inserta un instituto jurídico novedoso denominado por la presente investigación como «ejecución especial de sentencia apelada», mecanismo que establecerá la procedencia del pedido de ejecutar la sentencia desestimatoria para que sea ejecutada aún haya sido apelada por el demandante; por tanto, siendo un mecanismo de naturaleza procesal que se corresponde con el deber general de los órganos jurisdiccionales de administrar e impartir justicia, este proyecto normativo no irrogará gasto alguno al tesoro público; y por el contrario, los beneficios obtenidos a partir de la promulgación de este proyecto de ley serán notorios, pues se contribuirá a la sanción oportuna de las infracciones administrativas, y con ello, se erradicará el desprestigio de las instituciones públicas al momento de imponer el principio de autoridad; concretamente: las infracciones administrativas, como por ejemplo, apertura de locales de expendio de bebidas 
alcohólicas sin autorización, construcción en área pública sin autorización, etc., serán sancionadas oportunamente después de haberse desestimado la demanda en primera instancia.

\section{Limitaciones}

Se presentó la dificultad consistente en la actitud reacia a contribuir como entrevistado o encuestado (según el caso) por parte de los sujetos a quienes se aplicarán los instrumentos de recolección de datos; otra dificultad fue el riesgo latente para el investigador, pues recordemos que muchos de estos administrados infractores forman parte de grupos de poder, lo que implicaba riesgo para la integridad del investigador.

\section{Resultados}

1. Haciendo la revisión bibliográfica de este artículo, se tiene que: es posible para el demandante pedir la ejecución de la sentencia, a pesar de que esta ha sido apelada con el fin de evitar una dilación innecesaria; sin embargo, esta institución no procede para el demandado que, en un proceso sobre nulidad de resolución administrativa de sanción, vendría a ser la Municipalidad Distrital de Wánchaq.

2. Fundamentación, de la que se infiere que la Municipalidad Distrital de Wánchaq, por ser parte demandada en el proceso sobre nulidad de resolución administrativa de sanción, no puede solicitar la medida cautelar por sentencia favorable, pues esta medida - al tener un carácter instrumental - solo asegura la eficacia de una pretensión principal, que no la tiene la municipalidad demandada. Este indicador demuestra que el mismo ordenamiento jurídico al no permitir la ejecución anticipada de la sentencia favorable, aunque esta haya sido apelada a favor de la municipalidad demandada, se convierte en un mecanismo utilizado por los administrados infractores para dilatar la impunidad de su infracción.

3. Se aplicó la técnica de entrevista, dirigida a personalidades que se caracterizan por tener una apreciación técnico legal sobre el problema, como el juez, el fiscal, el procurador público encargado de la defensa, la ejecutora coactiva de la municipalidad y la entrevista a dos ciudadanos vecinos de las discotecas, que representan la opinión del vecindario; para ello, se elaboró un formato de entrevista el mismo que sirvió para describir de manera somera el problema y ubicar al entrevistado y, principalmente, para obtener su apreciación técnico legal sobre la pertinencia o no de la propuesta de ley, que establezca la ejecución especial de sentencia apelada en favor de la municipalidad demandada, cuando de por medio se vulnere el interés público.

4. Se aplicó la técnica de revisión de expedientes judiciales a la población en investigación, la misma que está conformada por 53 procesos sobre nulidad de resolución administrativa de sanción registrándose: la fecha de inicio del proceso judicial, la fecha de emisión de la sentencia de primera instancia, la fecha de emisión de la sentencia de segunda instancia; datos que nos permiten identificar el promedio de tiempo que toma conseguir una sentencia firme que posibilite la ejecución de la sanción administrativa.

5. Se aplicó la técnica de la observación al funcionamiento de bares y cantinas, sobre todo las que funcionan en la Av. Confraternidad del distrito de Wánchaq, lugar más representativo para la investigación. Para la medición de este indicador, se aplicó la técnica de la observación a través del registro fílmico proporcionado por el área de Ejecución Coactiva de la Municipalidad Distrital de Wánchaq, pudiéndose registrar: ebrios miccionando en las calles, riñas callejeras, congestión vehicular, alcoholismo, etcétera.

\section{Discusión}

Los resultados obtenidos a partir de la aplicación de los instrumentos de recolección de datos para la medición de los indicadores de cada variable, pueden interpretarse de la siguiente forma:

- Indicador 1 de la variable independiente. Consistente en el artículo 615 del CPC, que reconoce la procedencia de medida cautelar por sentencia favorable, solo para el demandante, dentro de un proceso contencioso sobre nulidad de resolución administrativa; es decir, nunca procederá esta medida cautelar para la demandada Municipalidad Distrital de Wánchaq, por lo que, de obtenerse una sentencia que declare infundada la demanda del infractor, esta si es apelada, seguirá suspendiendo la ejecución de la sanción administrativa hasta obtenerse sentencia firme. El estudio de este indicador demuestra que la teoría de las medidas cautelares suple la limitación conceptual del artículo 615, ya que una medida cautelar tiene naturaleza instrumental, en tal sentido, solo obedecen a pretensiones — en el caso concreto al ser la municipalidad la parte demandada — esta no tiene una razón por la cual no le ampara el contenido del artículo 615 del CPC. El estudio de este indicador, también sugiere el empleo de este artículo como base para la confección del instituto propuesto por la investigación para la solución al problema, que se denomina ejecución especial de la sentencia apelada; por lo que, es necesario para la solución del problema la implementación del instituto de ejecución especial de sentencia apelada. 
- Indicador 2 de la variable independiente. Consistente en el auto de improcedencia de medida cautelar por sentencia favorable, interpuesta por la Procuraduría de la Municipalidad Distrital de Wánchaq, en el proceso judicial sobre nulidad de resolución administrativa de sanción n. ${ }^{\circ}$ 00478-2012, tramitado ante el 1. Juzgado Mixto de Wánchaq. El estudio de este indicador nos demuestra la carencia de sustento normativo para la viabilidad de la ejecución especial de la sentencia apelada, a efectos de resguardar el interés público y, en consecuencia, de ejecutar urgentemente las sanciones administrativas sin necesidad de esperar la obtención de una sentencia firme en segunda o tercera instancia, es decir, la falta del reconocimiento normativo del instituto propuesto por la investigación, consistente en la ejecución especial de sentencia apelada imposibilita al juez atender la petición de ejecución de la sanción administrativa mientras se tramite el proceso judicial en 2a y 3a instancias, por lo que, este indicador demuestra la pertinencia de establecer normativamente la ejecución especial de sentencia apelada que servirá como sustento para que el órgano jurisdiccional pueda atender la petición de la procuraduría, consistente en la ejecución de las sanciones administrativas en forma perentoria, pese a la presencia del proceso judicial.

- Indicador 3 de la variable independiente. Que trata de la implementación de la ejecución especial de sentencia apelada. Para la medición de este indicador, se aplicaron entrevistas a abogados involucrados en el desarrollo del problema quienes, desde una perspectiva técnico legal, señalan su posibilidad de solución; de igual forma, se realizaron entrevistas a dos vecinos notables de la Avenida Pumachahua, zona aledaña al funcionamiento sin autorización de las discotecas de la Avenida Confraternidad, los que, desde su punto de vista, sugieren una solución al problema.

El primer grupo de entrevistados está integrado por abogados involucrados en el desarrollo del problema — como el procurador y la ejecutora coactiva de la Municipalidad Distrital de Wánchaq, también el fiscal en lo contencioso administrativo que se encarga de emitir opinión previa a la sentencia y la apreciación de un juez- la entrevista a estas personas, arroja la inclinación por la implementación de un instituto jurídico que establezca la ejecución especial de sentencia apelada en favor de la municipalidad demandada, la misma que deberá ser implementada a través de un proyecto de ley. Igual parecer tienen los vecinos entrevistados.

- Indicadores 1 y 2 de la variable dependiente. Se refiere al periodo que le toma al juzgado emitir una sentencia firme, lo que significa el tiempo durante el cual se suspende la ejecución de la sanción administrativa. Para la medición de este indicador, empleamos la técnica de revisión de los expedientes judiciales, registrando las fechas en el cuadro Excel (anexo 01) y, para ilustrar los resultados se elaboraron los estadígrafos que muestran el prolongado tiempo que toma al órgano jurisdiccional emitir una sentencia firme. En el caso de los procesos que obtuvieron sentencia firme en primera instancia en promedio, tuvieron que transcurrir 1 156, 2 días desde la fecha de fiscalización y la emisión de la sentencia firme.

Luego, en los procesos que terminaron en segunda instancia, tuvieron que transcurrir, en promedio 1213,95 días, entre la fecha de fiscalización y la fecha de emisión de la sentencia firme.

Con respecto a los procesos que terminaron en la tercera instancia: 1 593,6 días transcurrieron entre la fecha de fiscalización y la fecha de emisión de sentencia casatoria.

Resultados que evidencian el tiempo de tres años como mínimo para la emisión de una sentencia firme que posibilite la ejecución de la resolución administrativa de sanción.

- Indicador 3 de la variable dependiente. Este indicador estriba sobre el funcionamiento de las discotecas de la Avenida Confraternidad. Para la medición se aplicó la técnica de la observación, registrándose a través de la filmación: el video evidencia, que el funcionamiento de las discotecas ubicadas en esta principal avenida del distrito de Wánchaq, origina la presencia de personas ebrias miccionando, riñas dentro y fuera de las discotecas, consumo de bebidas alcohólicas en plena calle, congestionamiento vehicular, comercio ambulatorio, etc., los mismos que demuestran la intranquilidad y la inseguridad que se desarrolla en la Av. Confraternidad y aledaños.

La medición de los indicadores ha posibilitado la obtención de resultados y su interpretación en favor de la hipótesis planteada, que es:

«Dado que; la ejecución especial de la sentencia apelada se implementará a través de una ley, esta contribuirá como mecanismo legal para que los jueces puedan disponer la ejecución oportuna de la sanción administrativa, a pesar de que la sentencia haya sido apelada.»

Es decir, frente a la impunidad de las infracciones administrativas que se originan por el mismo ordenamiento jurídico, que establece la suspensión de las sanciones municipales si estas han sido judicializadas, hasta la emisión de una sentencia firme; la hipótesis se convierte 
en la solución más acertada para el problema, pues busca la ejecución de la sanción administrativa a pesar de que esta ha sido judicializada a través de la implementación normativa del instituto de ejecución especial de sentencia apelada en los procesos sobre nulidad de resolución administrativa de sanción, con la finalidad de asegurar el interés público y se efectivice la sanción administrativa.

\section{Conclusiones}

Primera. La implementación de la ejecución especial de la sentencia apelada, a través del proyecto de ley propuesto, solucionará el problema identificado en el distrito de Wánchaq, y también servirá para extenderse a todo el país, pues el problema de la suspensión de las acciones administrativas por la interposición de procesos judiciales es generalizado en todo el ámbito nacional; por ello, el proyecto de ley propuesto una vez aprobado posibilitará que las municipalidades demandadas cuando obtengan sentencia desestimatoria, puedan pedir la ejecución inmediata de la sentencia que, a su vez, dispondrá la ejecución de la sanción administrativa.

Segunda. El problema de la falta de ejecución oportuna de las resoluciones administrativas de sanción se origina cuando la Municipalidad Distrital de Wánchaq, emite una resolución de sanción contra una falta administrativa, la misma que es suspendida en su ejecución cuando es judicializada por los administrados, de este modo se consolida la impunidad de las infracciones.

Tercera. Los factores que imposibilitan las ejecuciones oportunas de las resoluciones administrativas de sanción son de naturaleza legal, como el artículo 16.1.e) de la Ley del Procedimiento de Ejecución Coactiva y, el artículo 13 de la Ley Orgánica del Poder Judicial, disposiciones legales que establecen la suspensión de las sanciones administrativas por su revisión judicial.

\section{Referencias bibliográficas}

Ángeles C, C. (1999). La tesis universitaria en derecho: la investigación jurídica. Lima, Perú: San Marcos.

Ascención U., F. (2011). Sociología jurídica. Lima, Perú: Fondo Editorial UIGV - Sistema a distancia.

Bendezú Neyra, G. (2002). Derecho procesal administrativo: exégesis y casuística. Lima, Perú: FECAT.

Carrasco Díaz, S. (2009). Metodología de la investigación científica. Lima, Perú: San Marcos.

Castillo Q., Máximo; Sánchez B. Edwar. (2007). Manual de Derecho Procesal Civil. Lima - Perú. Jurista Editores. Lima, Perú: Jurista Editores.

Cervantes Anaya, D. (2014). Manual de derecho administrativo (7. ed.). Lima, Perú: Rhodas SAC.

Chanamé Orbe, R. (2009). Comentarios a la constitución : historia, análisis, evaluación (4.ta ed.). Lima, Perú: Jurista Editores.

Dómenech Pascual, G. (setiembre . diciembre de 2014). Por qué y cómo hacer análisis económico del derecho. Revista de Administración Pública(195), 99-133.

Fernández Vásquez, J. A. (2014). El paradigma del análisis económico del derecho y la legitimación de la crisis de la autonomía privada. (U. d. Sipán, Ed.) Revista Jurídica Científica SSIAS, 7(1). Recuperado el 5 de octubre de 2018, de http://revistas.uss.edu.pe/index.php/SSIAS/article/view/156

García Belaunde, D. (2003). Estado y municipio en el Perú. (UNAM, Ed.) Anuario de Derecho Constitucional Latinoamericano, 397 416. Recuperado el 5 de octubre de 2018, de http://historico.juridicas.unam.mx/publica/librev/rev/dconstla/cont/2003/pr/pr22.pdf

Hernández S. R., Fernández-Collado C., y Baptista L. P. (2006). Metodología de la investigación (4.ta ed.). (U. Iberoamericana-México, Ed.) México DF, México: McGraw-Hill. Recuperado el 5 de octubre de 2018, de https://investigar1.files.wordpress.com/2010/05/1033525612-mtis_sampieri_unidad_1-1.pdf

Hernández S. R., Zapata S. N., y Mendoza T. C.P. (2013). Metodología de la investigación para bachillerato: enfoque por competencias. México DF, México: McGraw Hill Interamericana.

Lora Cam, J. F. (2012). Filosofía de la educación: emergencia educativa. Lima, Perú: Juan Gutemberg Editores Impresores E.I.R.L. 
Lora Cam, J. F. (2013). Filosofía antimitológica, antiteológica, antihermenéutica (10.a reimpresión (1986) 1.ra ed.). Lima, Perú: Juan Gutemberg Editores Impresores E.I.R.L. Recuperado el 5 de octubre de 2018, de

https://es.scribd.com/document/336933261/Filosofia-Anti-mitologica-Anti-teologica-Anti-hermeneutica-Jose-F-W-Lora-Cam

María Hernández, A. (2003). Derecho municipal: Parte general. (UNAM, Ed.) México DF, México: Instituto de investigaciones jurídicas. Recuperado el 6 de octubre de 2018, de

http://www.inafed.gob.mx/work/models/inafed/Resource/322/1/images/Derecho_Municipal_Antonio_maria_hernandez.pdf

Masías Zavaleta, D. (2014). El proceso de investigación científica : ¿el por qué?, ¿el qué?, ¿el para qué? y ¿el cómo?, de la tesis de pre y posgrado. (Qosqo, Ed.) Cusco, Perú: Impresiones Pantigoso.

Monroy Gálvez, J. (1996). Introducción al proceso civil. (D. B. Monroy, Ed.) Santa Fe de Bogotá, Colombia: Temis S.A. Recuperado el 1 de octubre de 2018, de http://facultad.pucp.edu.pe/derecho/wp-content/uploads/2015/03/material2014.pdf

Morante Guerrero, L. E. (2014). Régimen jurídico del procedimiento contencioso administrativo. Lima, Perú: Pacífico Editores.

Perú, C. d. (11 de abril de 2001). Ley del Procedimiento Administrativo General. Ley N. ${ }^{2}$ 27444. Lima, Perú: Congreso de la República del Perú. Obtenido de https://www.indecopi.gob.pe/documents/20795/225805/07.+Ley+del+Procedimiento+Administrativo+General++Ley+27444.pdf/725a60ce-7f01-4542-9e1f-82ac40dd5810

Ramos Núñez, C. (2007). Cómo hacer una tesis de derecho y no envejecer en el intento (4.ta (1.ra junio 2000) ed.). (G. J. S.A., Ed.) Lima, Lima: Imprenta Editorial El Búho E.I.R.L. Recuperado el 3 de octubre de 2018, de https://www.academia.edu/28417528/COMO_HACER_UNA_TESIS_DE_DERECHO_Y_NO_ENVEJECER_EN_EL_INTEN TO_-_CARLOS_RAMOS_NU\%C3\%91EZ

Ramos Suyo, J. A. (2008). Elabore su tesis en derecho pre y postgrado (2.da ed.). Lima, Perú: San Marcos.

Ramunni Díaz, O. (2011). Filosofía. Lima, Perú: Fondo Editorial UIGV (Sistema a Distancia).

S/A. (2012). Código Civil y Código Procesal Civil Peruano. Lima, Perú: Jurista Editores E.I.R.L.

Solís Espinoza, A. (2008). Metodología de la investigación jurídico social (3.ra ed.). Lima, Perú: FECAT.

Witker, J. (1986). Cómo elaborar una tesis en derecho. Pautas metodológicas y técnicas para el estudiante o investigador del derecho. (E. P. México, Ed.) Madrid, España: Civitas S.A. Recuperado el 8 de octubre de 2018, de https://issuu.com/hdavalos/docs/como_elaborar_una_tesis_de_derecho_

Yaya Zumaeta, U. (2014). Las medidas cautelares en el derecho procesal civil peruano. Lima, Perú: IDEMSA.

Leyes y otros:

Ley n. ${ }^{\circ} 27444$ del Procedimiento Administrativo General. 11-04-01.

Resolución Legislativa del Congreso n. ${ }^{\circ}$ 1-2011-CR que aprueba el Reglamento del Congreso de la Republica. Lima-Perú.

Manual de Técnica Legislativa; aprobado por acuerdo n. ${ }^{\circ}$ 095-2010-2011/MESA-CR. LIMA-PERÚ.

Plan de Desarrollo Concertado de la Municipalidad Distrital de Wánchaq al 2013; aprobado mediante Ordenanza Municipal n. ${ }^{\circ 36-2003}$ del 02 de enero de 2004. Cusco-Perú.

Manual de Organización y Funciones (MOF) de la Municipalidad Distrital de Wánchaq. Cusco-Perú.

Reglamento de Organización y Funciones (ROF) de la Municipalidad Distrital de Wánchaq. Cusco-Perú.

Rev. Yachay volumen (7) Número (1), enero-diciembre 2018 